\title{
BALANCE HISTORIOGRÁFICO. Armadas y flotas en la España de los Austrias. Una relectura crítica
}

\author{
Porfirio Sanz Camañes \\ Universidad de Castilla-La Mancha \\ Porfirio.Sanz@uclm.es
}

La reedición en 2013 de una Historia Militar de España, dirigida por Hugo O'Donnell y Duque de Estrada, está llamada a convertirse en una obra de referencia para estudiosos e investigadores ${ }^{1}$. Los seis primeros volúmenes ya han visto la luz gracias al apoyo de la Comisión Española de Historia Militar ${ }^{2}$ y el patrocinio de la Fundación Ramón Areces. Los otros tres volúmenes restantes deben aparecer a lo largo de 2017 y 2018. Como apoyo a esta obra, se ha estado llevando a cabo un importante trabajo de investigación en el Archivo General de Simancas sobre el nombramiento de oficiales del Ejército y la Armada, que será incluido en forma de base documental como anexo a la Historia Militar de España ${ }^{3}$. Por fortuna, en este panorama historiográfico, dominado por el erratismo y la discontinuidad en la aparición de monografías y publicaciones, el primer volumen del tercer tomo está dedicado a la Edad Moderna y se centra en Ultramar y la Marina ${ }^{4}$. Como se señala en la introducción, el recorrido de este volumen abarca los siglos del reinado de la Casa de Austria y en él se recogen los aspectos comunes, literarios y artísticos que constituyen la mejor representación del impacto castrense en su entorno social ${ }^{5}$.

1 Nos referimos a la Historia Militar de España. III. Edad Moderna. I. Ultramar y la Marina, Madrid, Comisión Española de Historia Militar y Real Academia de la Historia, Ministerio de Defensa y Editorial Laberinto, 2013 (primera ed. 2009).

2 La Comisión Española de Historia Militar (CEHISMI) colabora con el Boletín Internacional de Bibliografía de Historia Militar proporcionando recensiones de los principales libros de contenido histórico que se publican en España. Además, representa a España en los congresos anuales internacionales de historia militar con ponencias desarrolladas por historiadores nacionales (civiles y militares) sobre el tema seleccionado en cada congreso.

3 El proyecto está siendo dirigido por E. García Hernán, investigador del CSIC y vocal de CEHISMI, mientras las tareas de compilación se han llevado a cabo por el hispanista inglés Phillip Williams.

$4 \mathrm{He}$ tenido la oportunidad de elaborar recientemente un balance historiográfico como preludio al libro de $\mathrm{H}$. O'Donnell y duque de Estrada (coord.), Historia Militar de España... El balance será recogido en el tomo VI de la Historia Militar de España. Estudios historiográficos. Glosario y cronología (en prensa, 2017).

5 H. O'Donnell y Duque de Estrada, en la "Introducción" al volumen de H. O'Donnell y duque de Estrada (coord.), Historia Militar de España..., pp. 9-14. La cita en la p. 9. 
Como toda obra enciclopédica tiene el mérito de intentar reunir las aportaciones más actualizadas realizadas por prestigiosos historiadores modernistas aunque su nacimiento, en el seno de instituciones militares, quizá no haya obtenido el reconocimiento o la difusión deseadas. Los estudios referidos a la historia naval española en época moderna no han recibido el mismo impulso que la reflexión producida a resultas del retorno de la historia militar en España. Un retorno que ha ensanchado sus fronteras, gracias a los nuevos enfoques y perspectivas objeto de análisis. Despreciada, acusada de preocuparse fundamentalmente de la narración de hechos bélicos y, cuando no, relegada a una historia de segunda clase, la historia militar ha experimentado durante las dos últimas décadas una auténtica eclosión historiográfica ${ }^{6}$.

Los retornos historiográficos se han venido produciendo en distintas disciplinas. Al igual que sucedió en su momento con la vieja historia política, tan constreñida por la explicación del acontecimiento, la historia militar se movía entre actores que tenían que ajustarse a un guión preconcebido: los ejércitos, las tácticas, la guerra, las armas, la geopolítica, la estrategia, etcétera. Son elementos que generalmente sirven también a los propósitos del estudio de la Marina que sigue en el marco de cierto reduccionismo bélico. La aparente incomprensión que ha existido entre los historiadores de lo militar y los militares historiadores en cuanto a metodologías a utilizar y sus distintos enfoques, no ha permitido demasiadas colaboraciones entre unos y otros hasta las últimas décadas. Sin embargo, como quedó demostrado por la andanada de publicaciones y de estudios monográficos aparecidos desde comienzos de nuestro siglo ${ }^{7}$, se ha incrementado notablemente la nómina de historiadores modernistas interesados en abordar cualquiera de los aspectos relativos a la historia militar. Si bien, una vez más, los relativos a la Marina o a la historia naval siguen claramente rezagados.

La tradición historiográfica en esta disciplina también ha seguido, como en tantas otras, el camino recorrido por historiadores foráneos. Cuando a comienzos de 1955 en pleno auge de la historia de los Annales, el historiador Michael Roberts pronunciaba una conferencia inaugural en la Queen's University de Belfast con el título “The Military Revolution, 15601660" (Belfast, 1956), pocos podían presagiar la serie de contribuciones a que daría lugar su reflexión sobre la materia. Poco importa hoy si las cuatro revoluciones a las que en su momento hizo alusión Roberts -la táctica, el tamaño de los ejércitos, la estrategia y las repercusiones de la guerra- fueron las únicas o si debían apreciarse, como algunos críticos indicarían más tarde, otras como la aparición de la educación militar especializada en las academias militares, las leyes "positivas" de la guerra y el nacimiento de una importante literatura sobre el "arte de la guerra". Lo importante fue el impacto de esta obra y las que le siguieron, gracias en buena medida al apoyo demostrado poco después por sir George Clark en sus "Conferencias Wiles" de Belfast que tomaron forma en su War and Society in the Seventeenth Century publicadas en Cambridge en 1958.

Su crítica de los componentes militares de la revolución abrió el camino a otra serie de aportaciones durante la década de los ochenta (Michael Dufy, Knud J. V. Jespersen,

6 Tomamos prestada la expresión del profesor Enrique Martínez Ruiz, quien la utilizó para la presentación del número monográfico dedicado a la historia militar, en Studia Histórica. Cit. en E. Martínez Ruiz, "La eclosión de la historia militar", Studia histórica. Historia Moderna, 25 (2003), pp. 17-25.

7 Nos referimos a revistas tan consolidadas dentro del panorama historiográfico como: Estudis. Revista d'Història Moderna, 27(2001); Manuscrits. Revista d'història moderna, 21 (2003); Studia Histórica. Historia Moderna, 25 (2003); Revista de Historia Moderna. Anales de la Universidad de Alicante, 22 (2004); y Millars. Espai i Història, 26 (2003). 
David A. Parrott...) $)^{8}$ y de los noventa (Jeremy Black, Brian M. Downing, David Eltis, René Quatrefages... $)^{9}$, que también tomaron como señuelo editorial dicho término. En 2000, Luis A. Ribot, en otra de sus geniales aportaciones, volvía a refrescar algunos de los momentos importantes de este debate relativos a la cronología asignada a la tan manida Revolución militar $^{10}$. Y todavía sin terminar la década Jeremy Black se cuestionaba su existencia en la revista History Today ${ }^{11}$. Por otra parte, el ensanchamiento de la historia militar hacia otros campos objeto de estudio, como ha sucedido con la New Military History en Estados Unidos $^{12}$, también ha conllevado un riesgo irremediable -como ha señalado Antonio Espino-y pasa porque la historia militar entendida como historia de la guerra esté en riesgo de perder su identidad ${ }^{13}$. Precisamente este mismo autor y en una síntesis historiográfica sobre la guerra en la época de los Austrias, con las obras aparecidas entre 1991 y 2000, llegaba a la conclusión de que faltaba mucho por hacer al margen de conocer mejor los aspectos sociológicos, el ejército de los Austrias como institución, el impacto de la guerra desde una óptica socio-económica, los aspectos técnicos (la arquitectura militar) y los culturales $^{14}$. Y en 2010, en un homenaje al profesor John H. Elliott, Cristina Borreguero se centraba en los "logros del Imperio español" para hacer descansar la conservación de la Monarquía Hispánica en la combinación del poderío militar y el diplomático manteniendo "un nivel operativo y de eficiencia muy notables, aunque a coste muy elevado" 15 . Sin embargo, a pesar de señalar ciertas prioridades estratégicas para conservar el dominio de las líneas de comunicación básicas, tanto terrestres como marítimas -gracias a sus galeones en el Atlántico y galeras en el Mediterráneo- no aparece ninguna mención al poder naval. Más recientemente, Davide Maffi, ha aportado una nueva interpretación sobre determinados aspectos del aparato militar terrestre de la monarquía de los Austrias. En su obra En defensa del Imperio, entiende que la Monarquía Hispánica no fue un gigante paralizado por su conservadurismo, inútil e incapaz, destinado inevitablemente al desastre final. Más al contrario, conservó hasta el final de la guerra grandes capacidades militares

8 M. Duffy (ed.), The Military Revolution and the State, 1500-1800, [Exeter], University of Exeter, 1980; K. J. V. Jespersen, "Social Change and Military Revolution in Early Modern Europe: some Danish Evidence", Historical Journal, XXVI (1983), pp. 1-13; y D. A. Parrott, "Strategy and Tactics in the Thirty Years War: the 'Military Revolution'”, Militärges-chichtliche Mitteilungen, XVIII, 2 (1985), pp. 7-25.

9 J. Black, A Military Revolution? Military change in European society, 1550-1800, London, Humanities Press, 1991; B. M. Downing, The Military Revolution and political change. Origins of Democracy and Autocracy in Early Modern Europe, Princeton, Princeton University Press, 1992; D. Eltis, The Military Revolution in Sixteenth Century, London, Barnes Noble Books, 1995; y R. Quatrefages, La Revolución Militar Moderna. El crisol español, Madrid, Ministerio de Defensa. Centro de Publicaciones, 1998.

10 L. A. Ribot García, "Types of Armies: Early Modern Spain", en Ph. Contamine (ed.), War and Competition between states, Oxford, Oxford University Press, 2000. pp. 37-68.

11 J. Black, A Military Revolution..., pp. 34-41.

12 La New Military History se ha centrado, fundamentalmente, en la realización de estudios sociológicos que analizan el impacto de la guerra y sus consecuencias desde una óptica de lo social. Sobre este asunto, baste recordar las atinadas reflexiones de C. Borreguero Beltrán, en sus "Nuevas perspectivas para la Historia Militar: la 'New Military History' en Estados Unidos”, Hispania: Revista Española de Historia, 186 (1994), pp. 145-177.

13 A. Espino López, en su "Presentación" al monográfico "La historiografía hispana sobre la guerra en la época de los Austrias. Un balance, 1991-2000" en Manuscrits, Revista d'Historia Moderna, 21 (2003), pp. 1415.

14 Ibídem., pp. 161-191.

15 C. Borreguero Beltrán, "Logros del Imperio español: el poder militar y diplomático", en D. García Hernán (ed.), La historia sin complejos. La nueva visión del Imperio español (estudios en honor de John H. Elliott), Madrid, Actas, 2010, pp. 99-135. La cita en la p. 135. 
para hacer frente a enemigos como Holanda y Francia que supieron aprovechar mejor los cambios introducidos desde comienzos del siglo XVII en el arte de la guerra ${ }^{16}$. El Imperio acabó condenado a la derrota pero no por el demérito de su propia estructura sino por el progresivo agotamiento hacendístico y demográfico. La Monarquía conservó, hasta mediados del siglo XVII, buenas capacidades en la defensa de sus territorios mientras las fuerzas armadas demostraron, durante este largo desafío, poseer una capacidad de recuperación en muchas ocasiones casi milagrosa ${ }^{17}$. Al hablar de estas fuerzas armadas se prescinde, una vez más, del poderío marítimo español. La reflexión a la que se llega en todas estas obras es bien sencilla: entre esas lagunas historiográficas se siguen situando los estudios sobre la Armada.

Hacer un balance de lo aparecido en lo que llevamos de siglo sobre la Marina obliga a dirigir una mirada rápida a la última década del siglo $X X$, casi a los aledaños de todo lo aparecido con objeto de dos conmemoraciones: la del IV Centenario de la Armada contra Inglaterra, en 1988; y la del V Centenario del Descubrimiento de América, en 1992.

Con motivo del IV Centenario de la Armada o la Empresa de Inglaterra se impulsaron los estudios sobre la "Jornada de Inglaterra", con el logro de incorporar a este escenario historiográfico, aunque con cierto retraso, la obra de algunos historiadores españoles. Desde el Instituto de Historia y Cultura Naval se apoyó la difusión de artículos especializados y de gran interés relacionados con la Armada ${ }^{18}$. La versión inglesa contó con el patrocinio institucional del National Maritime Museum de Greenwich, que apostó por un nuevo catálogo oficial, con el título Armada, 1588-1988 y en la publicación de la revista Royal Armada 400 Years, editada por Manorial Research, con un mayor enfoque divulgativo y comercial que científico en el tratamiento de los temas y escasa intención, eso también, de renovar el mito historiográfico. En 1989, todavía recordando los actos conmemorativos, aparecieron dos trabajos sobre la serie de actos culturales desplegados el año anterior y algunas obras de referencia publicadas con motivo de los mismos. El primero de ellos correspondió a una Nota crítica por parte de Alfredo Alvar, quien seleccionaba "siete obras sobre la Empresa de Inglaterra", de autores como José Luis Casado Soto, Carlos GómezCenturión Jiménez, Manuel Gracia Rivas, Hugo O'Donnell y Duque de Estrada y Fernando Riaño Lozano. A falta de una síntesis compartida, esta primera andanada historiográfica ofrecía un pormenorizado análisis de los aspectos coyunturales que rodearon la Empresa de Inglaterra y ampliaba las referencias de otros conocidos hispanistas anglosajones y franceses. La segunda aportación, con una selección bibliográfica sobre la Gran Armada, correspondió al Balance historiográfico realizado por David García Hernán. En un esfuerzo de apretada síntesis nos presentaba una acertada visión del aluvión de trabajos y estudios aparecidos sobre la Armada, que abarcaron desde las aportaciones científicas y rigurosas hasta las crónicas noveladas, teniendo en cuenta el atractivo del tema para un público en general ávido de sucesos históricos tan envueltos en los ropajes de singulares leyendas.

La segunda de las conmemoraciones se centró en el V Centenario del Descubrimiento de América o Encuentro con América y permitió la organización de numerosos congresos, jornadas y reuniones científicas sobre la preparación del viaje colombino, la figura del descubridor, las consecuencias del descubrimiento y su impacto en Europa, etcétera. El Archivo General de Indias de Sevilla se ha convertido en el auténtico catalizador de los

16 D. Maffi, En defensa del Imperio. Los ejércitos de Felipe IV y la guerra por la hegemonía europea (16351659), Madrid, Actas, 2014, p. 18.

17 Ibídem, pp. 515-517.

18 La Revista de Historia Naval (1988), dedicó el número 23 de su colección casi por completo a la Armada contra Inglaterra. 
estudios referentes al mundo americano. Bien es cierto que el papel de las flotas de Indias quizá ofrezca algún tipo de paralelismo con la organización naval del Viejo Mundo. A nadie puede escapar que la flota jugó un papel destacado en la unión de los territorios europeos de la Monarquía dispersos por Italia, norte de África, Canarias, Azores y los Países Bajos, siendo un puente hacia las posesiones del Atlántico y el Pacífico. En este sentido, estoy de acuerdo con Enrique García Hernán, al entender que la historia conjunta de las flotas de Indias sigue pendiente de estudio aunque conozcamos cada vez más cuestiones sobre el destino compartido de algunas de las armadas y flotillas españolas en Indias ${ }^{19}$. No cabe duda que el Atlántico ha sido un espacio marítimo y naval que ha sabido atraer la atención de los investigadores, aunque a diferencia de las obras aparecidas sobre el siglo XVIII -con los trabajos de Francisco Andújar, Alberto Marcos, Christopher Storrs, Agustín González y Rafael Torres, entre otros ${ }^{20}-$ la cosecha del Seiscientos es notablemente inferior destacando las aportaciones de Carlos Martínez Shaw ${ }^{21}$.

Con una década de diferencia cabe destacar el renovado impulso historiográfico aportado por otras dos notables iniciativas: el congreso internacional organizado con motivo de la Exposición Internacional de Lisboa; y una sección temática dedicada a los asuntos navales y marítimos en la X Reunión Científica de la Fundación Española de Historia Moderna celebrada en junio de 2008 y cuyas actas aparecieron al año siguiente.

Con motivo de la Exposición Internacional de Lisboa y bajo los auspicios de la Sociedad Estatal Lisboa'98 se puso en marcha una iniciativa de gran alcance historiográfico, con el título: Las sociedades ibéricas y el mar a finales del siglo XVI. A resultas del Congreso Internacional apareció la obra bajo la coordinación de Luis A. Ribot García y Ernest Belenguer Cebriá, publicada en seis volúmenes en 1998. Como señalaba en su presentación el Comisario General de España en la Expo, el profesor Luis M. Enciso, a finales de 1598 la Monarquía Hispánica se planteaba cuatro escenarios: el internacional, la situación financiera, el impacto demográfico y la crisis de algunos centros industriales y mercantiles de Castilla ${ }^{22}$. Precisamente, el segundo de los volúmenes puso énfasis en los recursos, la organización y las estrategias de la Monarquía. Distintos trabajos sometían a revisión el dispositivo militar y las implicaciones estratégicas de la política ibérica en Europa, América, África y Asia, además de dedicar varios estudios al análisis de las flotas y la tecnología navales. El esbozo historiográfico de Alberto Tenenti sobre el Mediterráneo después de la publicación de la primera edición del Mediterráneo de Braudel de 1949 abría un pórtico a cuestiones tan diversas como: "El cambio estructural del comercio español del siglo XVI" de Valentín Vázquez de Prada; y "Las rutas del mar y la crisis del orden imperial hispánico en el reinado de Felipe II" de José Alcalá-Zamora, autor que ponía su acento en el abandono de las rutas septentrionales y en la política limitada y miope de Lerma en África lo que derivó, lógicamente, en la debilidad naval española, clave de un edificio imperial indisolublemente ligado al dominio de los mares y de sus rutas ${ }^{23}$. La década

19 E. García Hernán, "War and Society in Spain. New Perspectives on the Military History of the Early Modern Period", International Bibliography of Military History, Brill, Leiden, 35 (2015), pp. 2-3.

20 Ibídem, pp. 5-6.

21 Véase, por citar algunas, las de: C. Martínez Shaw y M. Alfonso Mola, Europa y los nuevos mundos: siglos XV-XVIII, Madrid, Síntesis, 1999; y C. Martínez Shaw y J. M. Oliva Melgar, El sistema atlántico español, siglos XVII-XIX, Madrid, Marcial Pons, 2005.

22 L. A. Ribot García y E. Belenguer (coords.), Las sociedades ibéricas y el mar a finales del siglo XVI, tomo I, Lisboa, Sociedad Estatal Lisboa ,98, 1998, pp. 5-6.

23 J. Alcalá-Zamora y Queipo de Llano, "Las rutas del mar y la crisis del orden imperial hispánico en el reinado de Felipe II" en L. A. Ribot y E. Belenguer (coords.), Las sociedades ibéricas..., tomo II, p. 314. 
1588-1598, denominada de "desastres" por Geoffrey Parker se ocuparía de los desafíos de la política filipina en las postrimerías del reinado. Por otro lado, "La flota atlántica y la tecnología naval hispana" era analizada por José Luis Casado Soto, quien resaltaba que la supremacía tecnológica naval hispana durante el siglo XVI fue requisito indispensable para la conservación de la preponderancia económica, política y militar. A diferencia de las tesis mantenidas por George Modelski y William R. Thompson en su Seapower in Global Politics, 1494-1993 (Londres, 1988) o por Robert A. Stradling, en La Armada de Flandes. Política naval Española y Guerra europea, 1568-1668 (Madrid, 1992), centradas en la debilidad marítima española, José L. Casado ponía su acento en el crecimiento de la actividad en los astilleros españoles, en la temprana racionalización de los procesos de producción y control y en el desarrollo y transformaciones de las diversas flotas atlánticas hispanas para convertirlas en la primera potencia europea sobre la mar ${ }^{24}$. A continuación, David Goodman, incorporaba en "El dominio del mar y las Armadas de la Monarquía" un nuevo matiz a la tesis de la decadencia naval: las ciudades portuarias de Cádiz, Lisboa y Santander, junto a los ricos bosques cántabros y a su larga tradición pesquera y exploradora le otorgaban una considerable potencial naval ${ }^{25}$. En la aportación "Del Báltico al Índico: las nuevas fronteras hispánicas del siglo XVI" del profesor Jan Kieniewicz se lanzaba la mirada a dos nuevos espacios que requerían la atención de la monarquía filipina. El Báltico dejaba de convertirse en un mar interior para el Imperio para ser objeto de disputa entre polacos y rusos. Y, por otra parte, la suma del imperio luso al español pondría en manos de Madrid nuevas rutas hacia el Índico mientras en el Extremo Oriente nacía el Pacífico español ${ }^{26}$.

Los tomos III, V y VI se dedicaron al área del Mediterráneo, al área atlántica (Portugal y Flandes) y a las Indias respectivamente. La cuenca del Mediterráneo tuvo dos secciones de interés: la Corona de Aragón y los estados de Italia y la consolidación del sistema español. En la primera, se trataba la configuración política y estructura territorial de la Corona y solamente se incorporó un trabajo sobre el corsarismo mediterráneo de Gonzalo López Nadal. Con respecto a Italia, dominaban los trabajos sobre Nápoles y Sicilia, si bien centrados sobre sus Cortes virreinales más que sobre la dimensión marítima de estos reinos. La aportación atlántica quedó restringida a la figura de Felipe II en la historiografía portuguesa y flamenca. Sólo uno de los trabajos se centró especialmente en el sistema imperial español tras la unión ibérica y sus implicaciones internacionales tras la rebelión holandesa. La expansión holandesa en Asia, en la costa de África occidental, en Brasil, en el Caribe y en Norte América tuvo efectos militares y comerciales sobre el sistema ibérico bien es cierto que hasta 1621 con un impacto muy limitado. De lo que no cabe duda, según Piet C. Emmer, es de la coexistencia de ambos sistemas entre 1500 y 1800 desde África y Asia hasta el Nuevo Mundo $^{27}$. En el tomo referente a las Indias se incluyen aportaciones sobre América y sobre el dominio del Pacífico. Hay un amplio abanico de estudios que abarcan cuestiones políticas y geográficas (los descubrimientos, las Islas Canarias y las Azores), la economía indiana (y el tesoro americano), la sociedad colonial y las instituciones americanas bajo Felipe II. La defensa, el corsarismo y las fortificaciones están presentes en el trabajo de Luis Navarro

24 J. L. Casado Soto, "Flota atlántica y tecnología naval hispánica en tiempos de Felipe II" en L.A. Ribot y E. Belenguer (coords.), Las sociedades ibéricas..., tomo II, p. 358.

25 D. Goodman, "El dominio del mar y las Armadas de la Monarquía" en L. A. Ribot y E. Belenguer (coords.), Las Sociedades Ibéricas..., tomo II. p. 383.

26 J. Kieniewicz, "Del Báltico al Índico: las nuevas fronteras hispánicas a finales del siglo XVI" en L. A. Ribot y E. Belenguer (coords.), Las sociedades ibéricas..., tomo II. pp. 385-402.

27 P. C. Emmer, "Beyond the Line; Resisting Iberia outside Europe. The Dutch in Asia, Africa and the New World, 1590-1609" en L. A. Ribot y E. Belenguer (coords.), Las sociedades ibéricas..., tomo V, pp. 171-186. 
García quien vuelve a repasar el impacto del corso en la Carrera de Indias y en especial sobre distintas poblaciones del Caribe ${ }^{28}$. A resultas de las correrías de Drake aparecerá un dispositivo de fortines y fortificaciones de mayor entidad desde La Española a Cartagena de Indias a cargo de Bautista Antonelli. Si por parte española las construcciones militares en el Caribe permitieron la conservación de aquellos territorios, por parte de los corsarios la larga etapa de contrabandismo y saqueo contribuyó a la formación de un plantel de marinos y a la obtención de un considerable botín en metales preciosos y en productos locales, cuya venta permitió la acumulación de capitales que hicieron posible en la segunda mitad del siglo el comienzo de la colonización inglesa de Virginia ${ }^{29}$. La parte dedicada al Pacífico consta de tres trabajos que ponen su acento en las exploraciones españolas de Magallanes y Elcano por Leoncio Cabrero, el primer asentamiento español en Filipinas de Lourdes Díaz y el galeón de Manila de Pedro Ortiz Armengol. Por último, el tomo IV dedicado a "La Corona de Castilla" solo se centró de forma muy superficial sobre las cuestiones mercantiles del Consulado de Bilbao, la Andalucía atlántica, los cambios estructurales y de gestión económica de la Carrera de Indias y los conflictos de intereses derivados de la aplicación de las pragmáticas por los fletes en Guipúzcoa ${ }^{30}$. Según Carlos Martínez Shaw, si la Andalucía atlántica nunca había sido una región suficientemente industrializada en el Quinientos, el descubrimiento americano, la Carrera de Indias o el impacto desfavorable del comercio con el norte de Europa -como consecuencia de la revuelta de los Países Bajos y la derrota de la Invencible con el posterior saqueo de Cádiz en 1596- o el cierre del mercado norteafricano junto a la inestabilidad de las instituciones financieras sevillanas, fueron todos ellos factores que incidieron de muy diversa forma sobre el valle del Guadalquivir ${ }^{31}$.

La segunda iniciativa de notable valor e impacto historiográfico se produjo con motivo de la X Reunión Científica de la Fundación Española de Historia Moderna celebrada en Santiago y Ferrol entre el 11 y el 13 de junio de 2008. Una de las secciones temáticas estuvo dedicada a los asuntos navales y marítimos llevando por título El mar en los siglos modernos (O mar nos séculos modernos) cuyas actas fueron publicadas bajo el patrocinio de la Xunta de Galicia y la FEHM en 200932. El primero de los tomos, bajo la edición de Isidro Dubert y Hortensio Sobrado, se centraba en las gentes del mar y sobre todo en los comportamientos demográficos y familiares, así como en las economías y sociedades marítimas, con un total de cuarenta y una aportaciones, siete de ellas portuguesas. El segundo de los tomos, coordinado por Manuel-Reyes García Hurtado, Domingo L. González Lopo y Enrique Martínez Rodríguez, tuvo por objeto el control y el gobierno del mar, con treinta trabajos, y el mar en el interior, así como determinados aspectos culturales a modo de balance y perspectivas, con otros dieciocho estudios.

Precisamente, y en una excelente aportación a esta Reunión Científica, la profesora María del Carmen Saavedra reflexionaba sobre "la política naval y la guerra marítima

28 L. Navarro García, "Corsarismo y defensa: las fortificaciones indianas" en L. A. Ribot y E. Belenguer (coords.), Las sociedades ibéricas..., tomo V, pp. 161-178.

29 Ibídem, tomo VI, p. 178.

30 Se corresponde con las aportaciones de E. Fernández de Pinedo, M. Ruiz Trapero, C. Martínez Shaw, A. M. Bernal, A. García-Baquero, X. M. Pereira Fernández y X. Alberdi.

31 C. Martínez Shaw, "La Andalucía atlántica en el siglo XVI. Un primer despegue frustrado" en L. A. Ribot y E. Belenguer (coords.), Las sociedades ibéricas..., tomo IV, pp. 302-307.

32 I. Dubert y H. Sobrado, El mar en los siglos modernos (O mar nos séculos modernos), tomo I, Santiago de Compostela, Xunta de Galicia. 2009; y M. García Hurtado, D. L. González Lopo y E. Martínez Rodríguez, El mar en los siglos modernos (O mar nos séculos modernos), tomo II, Santiago de Compostela, Xunta de Galicia, 2009. 
del Antiguo Régimen", y dedicaba sus primeras y atinadas páginas al valor de estas conmemoraciones, considerando la celebración del Centenario de la Empresa "foco de renovación", permitiendo además la aparición de la colección "Gran Armada", editada por el Instituto de Historia y Cultura $\mathrm{Naval}^{33}$. La experta historiadora en temas navales destacaba, además, que obras como las de Francisco-Felipe Olesa Muñido, José Alcalá-Zamora, Irving A. A. Thompson o José Cervera Pery, entre otros, sirvieron de precursoras en un panorama historiográfico que en su vertiente naval parecía despertar de su letargo ${ }^{34}$. De hecho, la propia autora se considera heredera de la influencia del hispanista inglés Irving A. A. Thompson para publicar su Galicia en el camino de Flandes aparecida en $1996^{35}$. Sin embargo, como ella misma indica, la existencia de una escuadra gallega no prueba la provincialización de la guerra en los años treinta del siglo XVII ${ }^{36}$. En este sentido, no se puede vincular la eficacia de la organización militar a su grado de centralización o descentralización, ya que debemos saber cómo funcionó la escuadra, cómo se pagó, a quien sirvió y si la iniciativa fue o no tan novedosa ${ }^{37}$.

Con respecto al Mediterráneo, la política naval española cuenta con numerosos estudios en base al papel jugado por las galeras. El reinado de Felipe II comenzó con sus reformas en la administración para aumentar el número de galeras bajo control real directo. La política de expansión naval, según Irving A. A. Thompson, consiguió alcanzar la cifra de ciento sesenta y ocho galeras, multiplicando por diez el número de las que Fernando el Católico había dispuesto sesenta años antes y había triplicado al menos las que había conseguido tener Carlos $\mathrm{I}^{38}$. El estudio sobre los galeones y las galeras de John F. Guilmartin permitió conocer la predisposición de las plataformas sólidas y su capacidad para aguantar el peso de los cañones en las galeras desde comienzos del siglo XVI39. Los objetivos españoles en el Mediterráneo fueron de carácter defensivo porque se trataba de proteger las costas, el comercio y las comunicaciones de los corsarios y otros posibles asaltantes $^{40}$. El libro de Pardo Molero, publicado en 2001, es suficientemente clarificador

33 M. C. Saavedra Vázquez, "Política naval y guerra marítima en la España del Antiguo Régimen", en M. R. García Hurtado, D. L. González Lopo y E. Martínez Rodríguez (eds.), El mar..., tomo II, pp. 17-51.

34 Casi por las mismas fechas y en el Reino Unido la historiografía inglesa estaba en deuda con la reciente publicación del libro de I. A. A. Thompson, War and Government, en 1976, quien hacía una certera aproximación de los avances de la administración militar y los procesos de descentralización de la década de 1580. Las medidas aperturistas de Felipe II a comienzos de los 90 -para la atracción de extranjeros de la Europa del norte a España e instruirles en el arte de la marinería- o los galeones construidos mediante asiento para la monarquía de Felipe IV en la de 1620 fueron novedosas aportaciones a la luz de los conocimientos de la administración naval española de aquellos años. Otras tres obras causaban un notable impacto en la historiografía a finales de los 80. La obra de C. R. Philips, Six Galleons for the King of Spain (1986); y la de D. Goodman, con el título de Power and Penury, en 1988, cuyas traducciones al español en 1990 y 1991, renovaron la interpretación de la política naval del segundo de los Felipes. Por último, la obra de G. Parker y C. Martin sobre La Gran Armada, 1588 (Madrid, 1988), reeditada en 2011, que nos ha permitido conocer mejor, a la luz de la nueva documentación consultada y de los avances en la arqueología submarina, por qué los sucesos de la Armada acontecieron de ese modo en aquel verano de 1588. Véase, M. C. Saavedra Vázquez, "Política naval y guerra marítima...", tomo II, pp. 23-25.

35 M. C. Saavedra Vázquez, Galicia en el camino de Flandes. Actividad militar, economía y sociedad en la España noratlántica, 1556-1648, A Coruña, Ediciços do Castro, 1996.

36 M. C. Saavedra Vázquez, "Política naval y guerra marítima...", tomo II, p.29.

37 Ibídem, pp. 28-29.

38 I. A. A. Thompson, "Las galeras en la política militar española en el Mediterráneo durante el siglo XVl", Manuscrits, 24 (2006), p. 98.

39 J. F. Guilmartin, Galleons and Galleys, London, Cassell, 2003, pp. 114-117.

40 I. A. A. Thompson, "Las galeras en la política militar...", p. 104. 
sobre el esfuerzo naval español en Valencia durante el reinado de Carlos $\mathrm{V}$ incluyendo el apoyo de las oligarquías provinciales en las Cortes $^{41}$. La defensa de la cristiandad debía partir del control de las bases logísticas del norte de África como sucedió con el de la plaza fuerte de Orán ${ }^{42}$. Un espacio que ha sido bien explorado por las Armadas de Miguel Ángel de Bunes desde hace varias décadas ${ }^{43}$.

Ciertamente, las distancias en el Mediterráneo podían obstruir el operativo logístico, sobre todo si se contemplaba una hipotética invasión del Imperio Otomano mientras la estrategia española también estaba condicionada por sus escasos recursos navales. A fin de cuentas, hoy es plenamente aceptado que la victoria de la flota de galeras cristiana en Lepanto tuvo un valor simbólico y poco más. De hecho, como defiende Manuel Rivero, la Santa Liga jamás estuvo en condiciones de amenazar Estambul mientras los turcos se situaron en una posición que afectaba directamente a España, Italia y Portugal ${ }^{44}$. No cabe duda de que Lepanto, al igual que sucedió con la Gran Armada, se convirtieron en los dos acontecimientos sobre los que se focalizó el grueso de la investigación durante las décadas de los setenta y ochenta del pasado siglo ${ }^{45}$. A finales del siglo XVI -seguimos a I. A. A. Thompson- las galeras pasaron a desarrollar acciones más puntuales mientras se agrandaban las naves para recibir más cañones y más soldados. El desplazamiento del Mediterráneo al Atlántico y la sustitución de la galera por el galeón tuvo importantes consecuencias económicas y políticas para la Monarquía Hispánica, entre ellas, se dobló de manera súbita las demandas militares de hombres y de material, y este cambio logístico abarcó desde las áreas de relativa potencia en hombres, moral y disciplina hasta las áreas más débiles en barcos, cañones o especialización técnica ${ }^{46}$. Como ya insistía hace dos décadas Enrique García Hernán, la interpretación del "declive de España" resultaba un paradigma inapropiado para aproximarse a la historia bélica europea de los siglos XVI y $\mathrm{XVII}{ }^{47}$. De hecho, el Imperio otomano se manejaba con un modelo similar al de la Monarquía Hispánica, es decir, a través de la negociación entre las élites provinciales y el centro del Imperio en Estambul. En 2014, Phillip Williams publicaba su Empire and Holy War in the Mediterranean con el trasfondo de las grandes campañas en tiempos de Carlos V, Felipe II y Felipe III frente a los turcos. En efecto, la flota de galeras fue preservada por Carlos $\vee$ y

41 J. F. Pardo Molero, La defensa del Imperio. Carlos V, Valencia y el Mediterráneo, Madrid, Sociedad Estatal Para la Conmemoración de los Centenarios de Felipe II y Carlos V, 2001.

42 Véase, B. Alonso Acero, Orán-Mazalquivir, 1589-1639: Una sociedad española en la frontera de Berbería, Madrid, Consejo Superior de Investigaciones Científicas, 2000; y Cisneros y la conquista española del norte de África, Madrid, Ministerio de Defensa. Centro de Publicaciones, 2006. Junto a M. Á. Bunes, ambos como editores, Orán. Historia de la Corte Chica, Madrid,Polifemo, 2011.

43 Véase M. A. Bunes, La imagen de los musulmanes y del Norte de África en la España de los siglos XVI y XVII. Los caracteres de una hostilidad, Madrid, Consejo Superior de Investigaciones Científicas, 1989; del mismo autor, Los Barbarroja. Corsarios del Mediterráneo, Madrid, Alderabán Ediciones, 2004; "Felipe III y la defensa del Mediterráneo: la conquista de Argel", en E. García Hernán y D. Maffi (eds.), Guerra y sociedad en la Monarquía Hispánica. Política, estrategia y cultura en la Europa Moderna (1500-1700), vol. 1, Madrid, Fundación MAPFRE. Ediciones del Laberinto. Consejo Superior de Investigaciones Científicas, 2006, pp. 921946; y "La defensa de la Cristiandad. Las armadas en el Mediterráneo en la Edad Moderna", en Cuadernos de Historia Moderna. Anejos, 5 (2006), pp. 77-99.

44 M. Rivero Rodríguez, La batalla de Lepanto. Cruzada, guerra santa e identidad confesional, Madrid, Silex Ediciones, 2008, pp. 249-250.

45 M. C. Saavedra Vázquez, "Política naval y guerra marítima...", tomo II, p. 24.

46 I. A. A. Thompson, “Las galeras en la política militar...”, pp. 112-120.

47 E. García Hernán, La Armada española en la monarquía de Felipe II y la defensa del Mediterráneo, Madrid, Tempo, 1995 (la edición en inglés, Albatros, 2015). 
Felipe II en acciones militares como las de 1534 (Koron), 1554 (Mahdia), 1560 (Djerba), 1565 (Malta) y Túnez (1574). Unas decisiones que estuvieron determinadas, en su mayor parte, por las características de la armada otomana ${ }^{48}$. Sólo desde esta tesitura puede entenderse la paz en Italia, que obligó a la monarquía española a luchar en otros frentes a pesar de las dificultades para afrontar la guerra ${ }^{49}$. La política naval española del siglo XVIII tendría un importante turning point en las estrategias, impulsadas por Patiño, para reconquistar los territorios italianos y luchar contra la amenaza berberisca en el Mediterráneo ${ }^{50}$.

Me refería al comienzo de este balance al esfuerzo realizado, y no siempre reconocido, por parte de las instituciones militares y especialmente la Armada española por impulsar los estudios en historia política y militar. Quizá no esté de más recordar que la creación del Instituto de Historia y Cultura Naval, en 1976, resultó determinante para el fomento del estudio de la historia naval española. Entre sus funciones y cometidos, además de facilitar la investigación y publicar los resultados, se encuentra el de promover distintas actividades culturales centradas en la divulgación de la importancia del pasado naval español. Desde la dirección del Instituto también se realizan numerosas actividades anuales que consisten, por una parte, en las Jornadas de Historia Marítima sobre algún hecho o personaje relevante de la Armada; y, por otra parte, y con carácter trimestral, en la edición de la Revista de Historia Naval que, desde 1983, recoge y difunde trabajos y artículos de contenido histórico naval, de autores tanto nacionales como extranjeros, civiles o militares. Por último, se sigue editando la Revista General de la Marina que, con un tono divulgativo, todavía constituye para la Institución un referente profesional, histórico y cultural. Los dos departamentos de Historia y de Cultura Naval organizan y planifican las actividades del Instituto ${ }^{51}$.

Con el mismo sentido de aunar esfuerzos entre las instituciones militares y las civiles se creó en 1980 la Comisión Española de Historia Militar ${ }^{52}$, desde la que se ha coordinado el trabajo de los servicios históricos de los tres ejércitos ${ }^{53}$, sin olvidar atender a los compromisos internacionales que comportaba la adscripción de España a la Comisión Internacional de Historia Militar ${ }^{54}$. Los Congresos de Historia Militar también han favorecido, aunque no de la forma que hubiera sido necesaria, la investigación y divulgación sobre la temática de Ultramar y la Marina.

$48 \mathrm{Ph}$. Williams, Empire and Holywar in the Mediterranean. The Galley and Maritime Conflicto between the Habsburgs and the Ottomans, London y New York, 2014, pp. 13 y 16-17.

49 Ibídem, pp. 268-269.

50 La cita procede de la reseña de A. Crespo Solana al libro de M. Baudot Monroy, 2014. La cita en la revista Anuario de Estudios Americanos, 72 (2015). p. 765.

51 Desde este último, se han organizado las Jornadas de Historia Marítima, siendo responsable además de la publicación de los Cuadernos Monográficos del Instituto de Historia y Cultura Naval, con los contenidos de las conferencias impartidas durante las Jornadas y otros dedicados a personajes, acontecimientos, temas de interés o conmemoraciones centenarias.

52 La Comisión Española de Historia Militar (CEHISMI) ha organizado en España los Congresos Internacionales decimosexto en 1990 y trigésimo primero en 2005, ambos en Madrid.

53 Es decir, el Instituto de Historia y Cultura Militar (IHYCM) del Ejército de Tierra, el Instituto de Historia y Cultura Naval (IHYCN) y el Servicio Histórico y Cultural del Ejército del Aire (SHYCEA).

54 La Comisión Internacional de Historia Militar (CIHM), es la sucesora de la Comisión Internacional de Historia Militar Comparada, creada en 1938, y actúa como grupo de trabajo en el seno del Comité de Ciencias Históricas. El comité español tiene su sede oficial en la Real Academia de la Historia y en 1990 organizó en Madrid el XVII Congreso Internacional de Ciencias Históricas. La CIHM comenzó celebrando sus reuniones internacionales cada cinco años, en coincidencia con los congresos del comité de ciencias históricas, sin embargo, el interés suscitado y la necesidad de debatir ideas e intercambiar puntos de vista durante la Guerra Fría condujo a su carácter anual desde 1980. 
El trabajo conjunto entre las instituciones militares y las universidades ha tenido más luces que sombras. Los últimos proyectos se han convertido en auténticos referentes historiográficos. Sin embargo, no siempre fue así y otras iniciativas encallaron antes de alcanzar la mayoría de edad. Sirva el ejemplo de lo sucedido en 2003 cuando desaparecía, tras quince años de edición ininterrumpida con la edición de su número 17, la revista Militaria. Revista de Cultura Militar patrocinada desde la Universidad Complutense. La revista, que había nacido en el seno de la Asociación de Amigos del Museo del Ejército, y de la iniciativa de quienes pretendían combinar la cultura y el humanismo, salía a la luz en 1989, a las puertas de la preparación de la celebración del $V$ Centenario del Descubrimiento de América ${ }^{55}$. La presentación de su primer número, realizada por el entonces rector Gustavo Villapalos, tenía por objeto buscar caminos comunes entre la universidad y las instituciones militares, a través de las ciencias humanísticas ${ }^{56}$. En su primer número, contó con una aportación por parte de Fernando de Bordejé Morencos que, con el título "Los españoles y la mar", hacía una apología de la condición marítima española por razones geográficas, económicas y estratégicas ${ }^{57}$. Con un tono ciertamente pesimista por entonces animaba al inicio de estudios de historia marítima y naval que, por desgracia, resultaban poco comunes en la agenda de los investigadores españoles: "Aunque cuesta trabajo confesarlo y desde luego aceptarlo, hay que reconocer que en España ha existido, en realidad hasta ahora, un sector bastante amplio que apenas ha creído en la necesidad de llevar a cabo investigaciones y estudios sobre temas marítimos, y menos aún estratégicos"58. Por ello, concluía: "De ahí que la historia naval española permanezca aún inédita, entre el olvido, el silencio, o lo más, la apología triunfalista parcial"59.

Por fortuna, entre las luces que siguen brillando con luz propia contamos con varias iniciativas, materializadas sobre todo en torno a dos magnos congresos, que han tratado de poner al día los conocimientos en materia de historia militar y que han sido auspiciados por el Centro Superior de Estudios de la Defensa Nacional, la Comisión Española de Historia Militar y el Consejo Superior de Investigaciones Científicas.

En marzo de 2005 se celebró en Madrid el Congreso Internacional de Historia Militar que, con una amplia temática, abarcando desde la estrategia general y la organización del Ejército y la Marina, hasta sus relaciones con la sociedad civil y la cultura, reunió un importante número de conocidos investigadores. Al año siguiente y bajo la coordinación de Enrique García Hernán y Davide Maffi se editaron las actas con el título de Guerra y Sociedad en la Monarquía Hispánica (1500-1700), en dos volúmenes ${ }^{60}$, con más de dos mil páginas en su conjunto.

55 La revista Militaria, dedicó muy pocas páginas a la historia marítima o naval españolas. Prácticamente media docena de artículos de más del centenar publicados durante quince años. Además de los monográficos sobre Levante, Aragón, Navarra, Extremadura y Murcia, aparecieron números especiales sobre Cuba y Filipinas, y otros tres números extraordinarios dedicados al Congreso de 1993, al Museo del Ejército y a la Colección de Armería y de Historia Militar del Museo de San Telmo de San Sebastián.

56 G. Villapalos, "Presentación" de la revista Militaria. Revista de Cultura militar, 1 (1989), p. 9.

57 Fernando de Bordejé era por entonces Almirante y Director del Instituto de Historia y Cultura Naval. Véase, F. de Bordejé Morencos, "Los españoles y la mar", Militaria. Revista de Cultura militar, 1 (1989), pp. 27-37.

58 Ibídem, p. 27.

59 Ibídem.

60 E. García Hernán y D. Maffi, Guerra y Sociedad en la Monarquía Hispánica... En el segundo volumen no aparecen recogidos temas de historia militar naval y estuvo dedicado al Ejército y la sociedad civil, a la dimensión social y económica de la guerra y a la movilización de los recursos y al Ejército, la religión y la cultura. 
Cada uno de los volúmenes está dividido en tres secciones. El primer volumen, se divide en tres grandes bloques, y se inicia con el de "La Monarquía y sus adversarios: estrategia general y campañas militares", centrada en las revoluciones militares de la Edad Moderna y en los distintos estados en guerra. El segundo de los bloques se titula "La Monarquía y sus hombres: la organización del ejército", y pone énfasis en el soldado español, los campamentos militares, las innovaciones militares, el ejército de Flandes, la política defensiva, la defensa de la Monarquía y de los reinos, los servicios militares, el avituallamiento, las guardas de Castilla, la artillería, las guardas reales, la disciplina militar y los tercios españoles. Y, en el último se aborda la "Política naval, organización y guerra en el mar", con aportaciones centradas en el desarrollo de las armadas europeas y el poder español, de Jan Glete; la estrategia de la guerra de galeras en el Mediterráneo, de Philip Williams; la defensa española del Mediterráneo, de Miguel A. Bunes; o las escuadras venecianas y españolas a comienzos del siglo XVII, de Guido Candiani. Este bloque también dedicaba algunos trabajos a la construcción naval y la capacidad militar durante los Austrias; a los marineros de las galeras sicilianas; a la defensa naval del Atlántico; e incluso al rescate de los galeones naufragados en la monarquía de los Austrias.

Por otra parte, las actas del II Congreso Internacional "Guerra y Sociedad en la Monarquía Hispánica (1500-1700)" aparecerán, si el proceso editorial sigue su curso, a lo largo de 2017. Coordinado nuevamente por Enrique García Hernán, profesor de investigación del CSIC y Davide Maffi, profesor de la Universidad de Pavía, ha tenido como objeto poner al día las aportaciones científicas sobre el tema acaecidas durante los últimos dos lustros. Frente a la tradicional interpretación de que los enormes costes derivados de las campañas en los Países Bajos, el Mediterráneo, centro de Europa, Irlanda y del mantenimiento de las Indias habían llevado a la Monarquía al límite de su supervivencia y al declive de España, ha quedado demostrado en recientes estudios que los sucesos europeos tras la década de 1650 dejaron a una Monarquía en un segundo plano pero con una relevante estructura militar y organización naval y no solo en términos de recursos fiscales y humanos sino como organización singular ${ }^{61}$. En el encuentro se presentaron medio centenar de trabajos y contó con la asistencia de historiadores de una docena de países. Seguramente pronto se convertirá en un nuevo referente para los estudiosos de la historia militar al igual que ya lo son las actas del primer congreso.

Evidentemente el bagaje historiográfico de las últimas décadas sobre la historia naval española, en especial la referida a los Austrias, se ha encontrado demasiado condicionado por diferentes aspectos como ha señalado muy bien María del Carmen Saavedra Vázquez ${ }^{62}$. Por una parte, han destacado la aparición de obras eruditas y descriptivas, por lo general, escritas por profesionales de la Armada. Además, los estereotipos o clichés también han dominado sobre todo al referirse a distintas batallas o empresas como Lepanto, la Invencible o Trafalgar, ya en el siglo XIX. Tampoco se ha producido una revitalización historiográfica que aborde la temática en toda su amplitud, faltando estudios comparativos sobre la historia naval de otros países europeos. Por si fuera poco, la escasez de tesis sobre la materia leídas en las universidades españolas durante los últimos treinta años también ofrece una parca cosecha, a tenor de la gran cantidad de asuntos pendientes y el gran volumen de documentación disponible. De igual forma, supone un contratiempo la escasa proyección internacional que alcanzan los estudios en torno a la presencia española y del mundo hispano. Por ello, y como concluía Saavedra Vázquez, la confluencia de todos los factores

61 E. García Hernán, "War and Society in Spain...", p. 8.

62 M. C. Saavedra Vázquez, "Política naval y guerra marítima...", tomo II, pp. 19-22. 
enumerados proporciona una imagen de la política naval y la guerra marítima en la España moderna tan desigual como heterogénea ${ }^{63}$.

63 Ibídem, tomo II, p. 22. Por fortuna, se aprecian leves signos de cambio a esta escasa proyección internacional como ha puesto de manifiesto la investigadora del CSIC Ana Crespo Solana en sus proyectos europeos. En su opinión, el establecimiento de nuevas rutas comerciales conllevó la necesidad de barcos armados y galeones lo que supuso una mayor intensificación en la construcción naval y la demanda de madera en proporciones hasta entonces desconocidas, haciendo que la gestión forestal y el poder marítimo se interrelacionaran de tal forma que se crearan nuevas tensiones geo-políticas y alianzas con estos fines. 